\title{
GENERALIZATIONS OF STEINBERG GROUPS
}




\section{SERIES IN ALGEBRA}

Editors: J. M. Howie, D. J. Robinson, W. D. Munn

Vol. 1: Infinite Groups and Group Rings ed. J. M. Corson et al.

Vol. 2: Sylow Theory, Formations and Fitting Classes in Locally Finite Groups

M. Dixon

Vol. 3: Finite Semigroups and Universal Algebra

J. Almeida 
SER IES IN ALGEBRA VOLUME 4

\section{GENERALIZATIONS \\ OF STEINBERG \\ GROUPS}

\section{T A Fournelle K W Weston}

Department of Mathematics University of Wisconsin-Parkside USA 


\section{Published by}

World Scientific Publishing Co. Pte. Ltd.

P O Box 128, Farrer Road, Singapore 912805

USA office: Suite 1B, 1060 Main Street, River Edge, NJ 07661

UK office: 57 Shelton Street, Covent Garden, London WC2H 9HE

\section{Library of Congress Cataloging-in-Publication Data}

Foumelle, T. A. (Thomas A.)

Generalizations of Steinberg groups / T.A. Fournelle, K.W. Weston.

p. $\quad \mathrm{cm}$. -- (Series in algebra ; v. 4)

Includes bibliographical references (p. 225-226) and index.

ISBN 9810220286 (alk. paper)

1. Group theory -- Relations. I. Weston, K. W. (Kenneth W.)

II. Title. III. Series: Series in algebra ; vol. 4.

QA174.2.F68 1996

$512 \cdot .55-\mathrm{dc} 20$

96-29046

CIP

\section{British Library Cataloguing-in-Publication Data}

A catalogue record for this book is available from the British Library.

Copyright @ 1996 by World Scientific Publishing Co. Pte. Ltd.

All rights reserved. This book, or parts thereof, may not be reproduced in any form or by any means, electronic or mechanical, including photocopying, recording or any information storage and retrieval system now known or to be invented, without written permission from the Publisher.

For photocopying of material in this volume, please pay a copying fee through the Copyright Clearance Center, Inc., 222 Rosewood Drive, Danvers, MA 01923, USA. In this case permission to photocopy is not required from the publisher.

This book is printed on acid-free paper. 
For

\section{KATIE AND ISABELLE}


This page is intentionally left blank 


\title{
Preface
}

This book arose out of the joint work of the authors over the last six years. Some others have joined in this work at various times. Of these, Said Sidki has invested the greatest amount of effort. The direct origin of the book is a 1968 paper by the second author. A more recent paper in 1985 reawakened his interest in the subject. The first author became interested after this and with the help of the group theoretic programming language CAYLEY was able to shed some light on what groups admit verbal embeddings. While verbal embeddings at first seemed to be rather rare, computer calculations suggested that they were rather common. Moreover, the groups that appeared seemed very interesting. At this point the concept of verbal embedding was transformed into the concept of a linkage group and this was considered a method of constructing groups.

In order to describe further the groups that arise as linkage groups the authors were naturally led to the concept of a linkage Lie algebra and its associated Lie group. This in turn became to be considered as a method of constructing (usually infinite dimensional) Lie algebras.

This book describes all of the above concepts and many of the computer calculations and algorithms that led to these concepts. Some of the proofs may be a bit longer than they have to be. However, it seemed important in some sections to lengthen a proof to add clarity. The notation is generally standard and follows that of the books of D.J.S. Robinson which are listed in the bibliography. Note that functions and operators act on the right. Although some people feel uncomfortable with this, it seems natural to at least one of the authors.

Although the main intent of this work is to construct certain types of groups from a combinatorial point of view, it touches on many algebraic topics. These topics include finite simple groups, classical Lie algebras, infinite dimensional Lie algebras, the combinatorial theory of groups and algebras, Steinberg groups, and logic. However, it deals with these topics in a nonstandard manner. Thus, this work is somewhat experimental. It is hoped that it will be found interesting and useful.

\author{
Department of Mathematics \\ University of Wisconsin-Parkside
}


This page is intentionally left blank 


\section{Contents}

1 Verbal Embeddings 1

1.1 Introduction . . . . . . . . . . . . . . . . 1

1.2 Basic Theorems ................... . . . . . 7

1.3 General Verbal Embeddings ............... 13

2 Linkage Graphs and Linkage Groups 21

2.1 Linkage Graphs and Linkage Groups . . . . . . . . . . . . . . 21

2.2 Linkage Graphs From Verbal Embeddings . . . . . . . . . . . 28

2.3 Steinberg Groups and Graphs . . . . . . . . . . . . . . . . . . 34

2.4 Constant Groups That Cannot Arise . . . . . . . . . . . . 38

2.5 Regular Actions on Linkage Graphs . . . . . . . . . . . . . . . 44

2.6 Sporadic Groups and Linkage Groups . . . . . . . . . . . . . . 46

2.7 Counter Examples . . . . . . . . . . . . . . . 49

3 Combinatorics in Linkage Groups $\quad 63$

3.1 Free Products With Amalgamation . . . . . . . . . . . 63

3.2 The Collection Process . . . . . . . . . . . . . . 71

3.3 Termination of the Collection Process . . . . . . . . . . . . 74

3.4 The Normal Form Theorem . . . . . . . . . . . . . . 80

3.5 Consequences of the Normal Form Theorem . . . . . . . . . 81

3.6 Standard Linkage Graphs . . . . . . . . . . . . . . . 84

4 Linkage Lie Algebras and Groups 95

4.1 The Exponential Map . . . . . . . . . . . . . . 95

4.2 Generators and Relations in Lie Algebras . . . . . . . . 109

4.3 The Heptagonal Algebra . . . . . . . . . . . . . . . 116

4.4 A Description of $G_{2} \ldots \ldots \ldots \ldots 120 \ldots \ldots$

4.5 The Isomorphism Between $\mathcal{L}_{7}$ and $G_{2} \ldots \ldots \ldots$ 
5 Combinatorics In Linkage Lie Algebras 143

5.1 The Reduction Process . . . . . . . . . . . . . . . . . . 143

6 Computer Calculations $\quad \mathbf{1 5 5}$

6.1 Introduction . . . . . . . . . . . . . . . . 155

6.2 The Adjoint Representation of $\mathcal{L}_{7} \ldots \ldots \ldots \ldots$

6.3 The Adjoint Representation of $G_{2} \ldots \ldots \ldots$

6.4 The Isomorphism Between $\mathcal{L}_{7}$ and $G_{2} \ldots \ldots \ldots \ldots$

6.5 Embedding $\mathbf{Z}_{2}$ in $A_{5} \ldots \ldots \ldots \ldots \ldots . \ldots \ldots$

6.6 Embedding of $\mathbf{Z}_{3}$ into $S_{9} \ldots \ldots \ldots \ldots 18 \ldots \ldots$

6.7 Verbal Embedding of $\mathbf{Z}_{2}$ into $U(3,3) \ldots \ldots \ldots$

6.8 The Relations in $G_{2}(2)^{\prime} \ldots \ldots$. . . . . . . . . . . 192

7 Questions $\quad 221$

$\begin{array}{ll}\text { References } & 225\end{array}$

$\begin{array}{ll}\text { Index } & 227\end{array}$ 


\section{List of Figures}

1 A Basic Linkage . . . . . . . . . . . . . . . . . . . . 22

$2 \quad$ Linkage Graph for ST(3,R) . . . . . . . . . . . . 52

3 Linkage Graph for ST(4,R) . . . . . . . . . . . 53

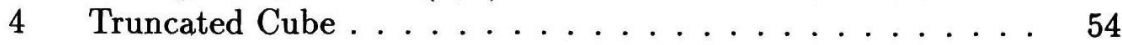

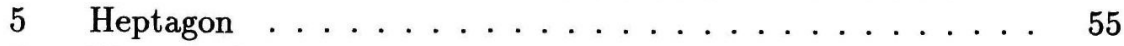

6 Hexagon $1 \ldots \ldots \ldots \ldots \ldots$

$7 \quad$ Hexagon $2 \ldots \ldots \ldots \ldots \ldots \ldots$

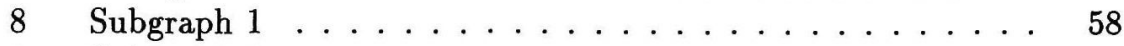

9 Subgraph $2 \ldots \ldots \ldots \ldots \ldots \ldots$

10 Subgraph $3 \ldots \ldots \ldots 60 . \ldots \ldots \ldots$

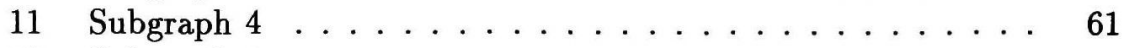

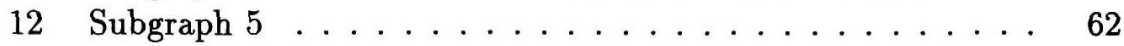

$1 \quad$ Linkage Graph $1 \ldots \ldots$. . . . . . . . . . . . . . . . . . . . . . 68

2 Linkage Graph $2 \ldots \ldots \ldots$. . . . . . . . . . . . . . . . . . . . .

$3 \quad$ Linkage Graph $3 \ldots \ldots . \ldots . \ldots . \ldots 87$

$4 \quad$ Linkage Graph $4 \ldots \ldots . \ldots . \ldots 8$

$5 \quad$ Basic Piece . . . . . . . . . . . . . . . . 89

6 Basic Piece .......................... 90

7 Heptagonal Linkage Graph . . . . . . . . . . . . . . . 91

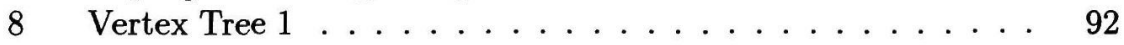

$9 \quad$ Vertex Tree $2 \ldots \ldots \ldots . \ldots \ldots$

1 Hexagonal Linkage Graphs . . . . . . . . . . . . . 113

$1 \quad$ Linkage Graph for A5 . . . . . . . . . . . . 181

2 Truncated Dodecahedron . . . . . . . . . . . . . . . 182 
This page is intentionally left blank 


\section{List of Tables}

4.1 Lie Multiplication Table . . . . . . . . . . . . . . . . 98

4.2 Heptagonal Lie Multiplication Table . . . . . . . . . . . 117

4.3 Heptagonal Lie Multiplication Table . . . . . . . . . . . 118

4.4 Characteristic 3 Lie Multiplication Table . . . . . . . . . 120

4.5 Partial Multiplication Table for G2 _ . . . . . . . . . . 122

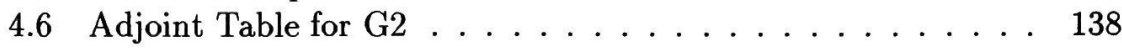

